\title{
Popliteal Artery Aneurysms
}

\section{Sidiki Keita ${ }^{*}$, Koniba Keita ${ }^{2}$, Moussa Sissoko ${ }^{1}$, Mamadou Coulibaly ${ }^{1}$, Lamine Soumare ${ }^{1}$, Oumar Sacko', Oulématou Coulibaly ${ }^{3}$, Sekou Koumaré1, Adama K. Koita ${ }^{1}$, Soumaîla Keita ${ }^{1}$, Zimogo Zié Sanogo ${ }^{1}$}

\author{
${ }^{1}$ General Surgery “A” Department, Hospital Point-G, Bamako, Mali \\ ${ }^{2}$ General Surgery Department, Hospital BSS, Kati, Mali \\ ${ }^{3}$ Reference Health Center of Commune VI, Bamako, Mali \\ Email: *sidikibafing@yahoo.fr
}

How to cite this paper: Keita, S., Keita, K., Sissoko, M., Coulibaly, M., Soumare, L., Sacko, O., Coulibaly, O., Koumaré, S., Koita, A.K., Keita, S. and Sanogo, Z.Z. (2021) Popliteal Artery Aneurysms. Surgical Science, 12, 127-134.

https://doi.org/10.4236/ss.2021.124015

Received: November 19, 2020

Accepted: April 20, 2021

Published: April 23, 2021

Copyright (c) 2021 by author(s) and Scientific Research Publishing Inc. This work is licensed under the Creative Commons Attribution International License (CC BY 4.0).

http://creativecommons.org/licenses/by/4.0/

\section{Open Access}

\begin{abstract}
A popliteal artery aneurysm is defined as a dilation of the popliteal artery greater than $20 \mathrm{~mm}$, or greater than $50 \%$ at diameter of the native artery. Popliteal artery aneurysms are rare, but are most common in the lower extremities. These aneurysms have a high risk of ischemic complications and amputations even in unoperated patients. We describe the case of a 54-year-old man, hypertensive, with a large popliteal artery aneurysm. Doppler ultrasound and CT angiography of the lower limbs showed a $100 \times 80 \mathrm{~mm}$ aneurysm of the popliteal artery. This aneurysm is responsible for venous compression with edema of the tissues under the skin. The patient was treated and a flattening of the aneurysm associated with bypass by the inverted right internal saphenous vein taken from the ipsilateral leg was performed. The patient was discharged on the 6th day of the operation. The patient was seen again at the outpatient clinic for one month and in the 3rd month an arterial Doppler ultrasound of the lower limbs performed had shown patency of the venous graft and disappearance of the intermittent claudication.
\end{abstract}

\section{Keywords}

Artery Popliteal, Aneurysm, Surgery

\section{Introduction}

\subsection{History}

Popliteal aneurysms have been known from ancient Egypt. By confining ourselves to the rigorous explanation of the word aneurysm or aneurusm, as the famous Von-Swieten wrote, we find that it comes from the Greek word which literally means dilation [1]. Rufus, of Ephesus, Aetius, Heister, Paul of Aegina, 
Galen, appeared to be the first to describe the aneurysm [1] [2]. The popliteal artery aneurysm was considered incurable; no other resource was known to save the patient's life than amputation of the limb. The anatomical details given by Heister suggested the possibility of undertaking popliteal artery surgery. Guallani in 1756, M. Pelletan, Desault in 1785, Jean Hunter performed the operation for the popliteal artery aneurysm for the first time. Hunter's method was first used in France in 1792 by Chopart [1].

Popliteal aneurysm is defined as a dilation of the popliteal artery greater than $20 \mathrm{~mm}$, or greater than $50 \%$ to the diameter of the native artery. Popliteal artery aneurysms (PAA) account for $70 \%$ of lower limb aneurysms. In its pathogenesis, arteriosclerosis seems to play an important role by weakening the arteries and their capacity for resistance [3]. Cardiovascular risk factors such as high blood pressure, tobacco, diabetes, obesity seem to play an important role in the onset of this disease. There are two clinical forms at the time of diagnosis. The asymptomatic form is present in a third of cases [3] [4]. The symptomatic form associates acute or chronic ischemia, compression of the veins, nerves, muscle and rupture of the aneurysm. The PAA is often referred to as the silent killer of the leg circulation. The diagnostic workup includes Doppler ultrasound, arteriography, CT angiography and MRI angiography. Open surgery and endovascular treatment now have an excellent patency rate and a low risk of amputation. This was the first case operated on in our department. The objective of this work was to describe this case and to evaluate the surgical result.

\subsection{Clinical Case}

Mr. S. C. aged 54, seen at the consultation for painful swelling in the right calf. His cardiovascular risk factor was poorly monitored high blood pressure; there was no previous surgical or family medical history. The onset of symptoms was marked by the appearance of a swelling in the right calf, painful, increasing in size for three years, without any notion of trauma, intermittent claudication less than 150 meters.

Physical examination revealed a painful, swollen, warm, right calf is tight and shiny (Figure 1). On vascular examination of the lower limbs, on the right only the femoral and popliteal pulses were present; on the left all the pulses were present. The rest of the vascular examination was normal.

An arterial and venous Doppler ultrasound of the lower limbs revealed a large aneurysm pocket measuring $101 \times 80 \mathrm{~mm}$ at the level of the upper $1 / 3$ of the posterior surface of the right leg in communication with the popliteal artery. This aneurysm is responsible for venous compression with edema of the soft tissues under the skin. The permeability of the other vascular axes of the two lower limbs is preserved.

The arterial CT angiography of the lower limbs performed by helical acquisition with synchronous injection of $80 \mathrm{ml}$ of telebrix, at a flow rate of $4 \mathrm{ml}$ per second. The iliac and femoral arteries are well opacified and of normal caliber. 


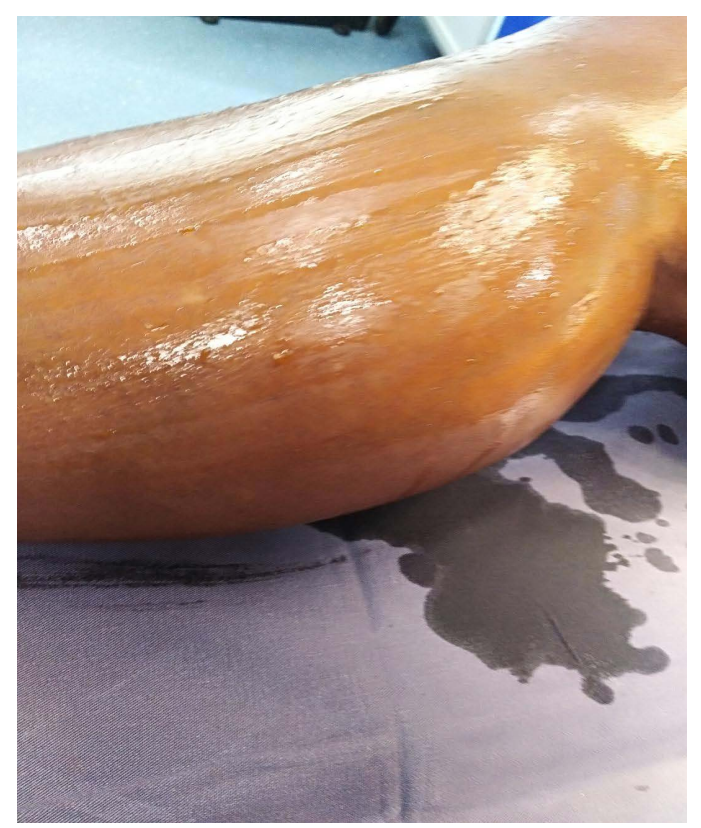

Figure 1. The right calf is tight and shiny.

Demonstration of a large sacciform dilation of the right popliteal artery measured at $10 \mathrm{~cm}$ high and $8 \mathrm{~cm}$ of thickness (Figure 2, Figure 3). The aneurysm shows a wall thrombosis $16 \mathrm{~mm}$ of thickness by location. The implantation base of the aneurysm is extended over $6 \mathrm{~mm}$ with acute connection angles as well as downstairs to upstairs which denotes its sessile character. There is an opacification weak underlying leg tripod artery. There is no detectable arterial stenosis on the right or on the left. Conclusion: large sacciform and sessile aneurysmal dilation of the popliteal artery with mural thrombosis.

Laboratory examinations at entry showed moderate microcytic anemia $(\mathrm{Hb}=$ $11 \mathrm{~g} / \mathrm{l})$, which increased in the first 24 hours of hospitalizations $(\mathrm{Hb}=10.7 \mathrm{~g} / \mathrm{l})$, signs of inflammation (CRP $=83 \mathrm{mg} / \mathrm{l})$, and the absence of hepatic cytolysis, cholestasis or thrombocytopenia. The diagnosis of a large aneurysmal dilation has been retained and the patient was put on initial medical treatment with standard heparin lasting two days.

The patient is admitted to the operating room because of the painful nature of the aneurysm. He was installed in the supine position with the leg flexed on the thigh. General anesthesia was performed with invasive monitoring of vital parameters of blood pressure, heart rate, electrocardiogram, pulse, respiratory rate, oxygen saturation. A first sample of the right internal vein at the level of its tibial segment had been carried out. A classic medial approach with exposure of the upper and lower popliteal artery allowing to control the proximal (Figure 4) and distal neck of the aneurysm. Exploration showed a large aneurysm sac and pain in the crow's feet muscles (Figure 5). The intervention then consisted of flattening the aneurysm associated with end-to-side venous bypass between the inverted saphenous vein and the popliteal artery above and the posterior tibial artery. The gesture went without incident, the peripheral pulses did not return, 


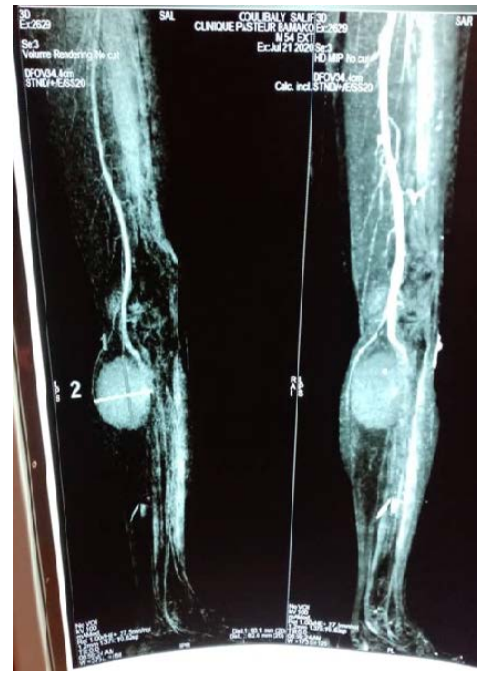

Figure 2. Demonstration of a large sacciform dilation of the right popliteal artery.

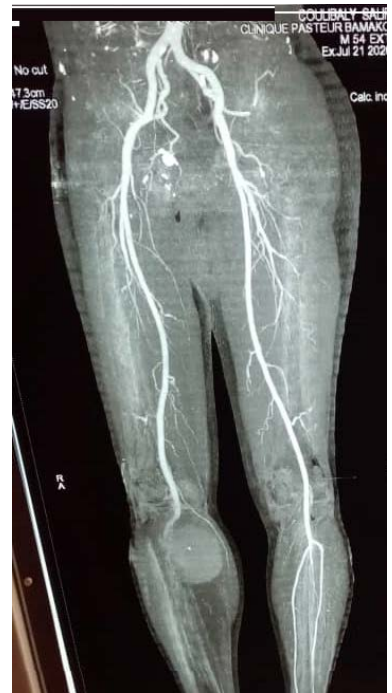

Figure 3. Demonstration of a large sacciform dilation of the right popliteal artery.

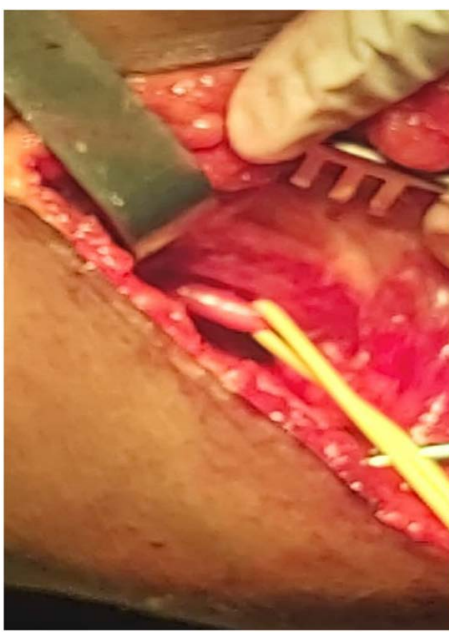

Figure 4. Control the proximal and distal neck of the aneurysm. 


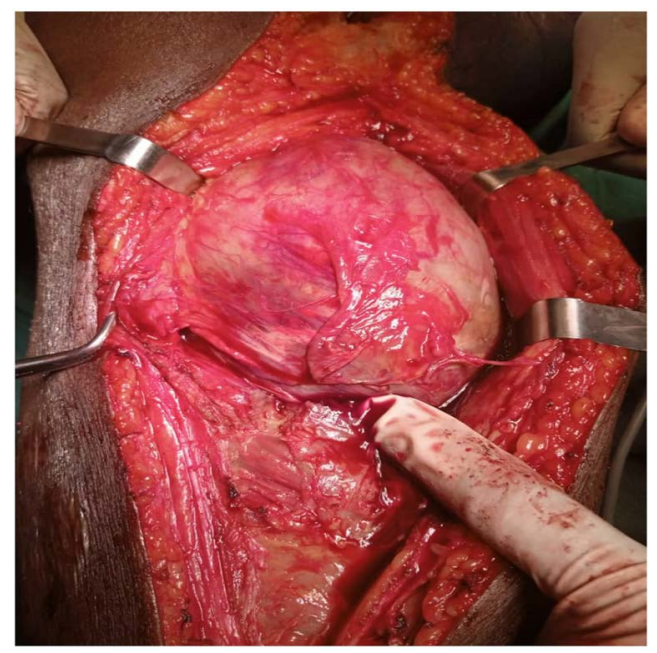

Figure 5. Large aneurysm sac.

the limb was warm and there was no motor deficit. The patient was put on treatment with standard heparin, a double antiplatelet agent and the converting enzyme inhibitor. The patient was discharged on the 6th day of the operation. The patient was seen again at the outpatient clinic for one month and in the 3rd month an arterial Doppler ultrasound of the lower limbs performed had shown patency of the venous graft and disappearance of the intermittent claudication.

\section{Discussion}

Popliteal artery aneurysms account for $70 \%$ of lower limbs aneurysms. Its incidence varies from $0.1 \%$ to $2.8 \%$ [3] [5]. The man is most often affected; half of these aneurysms are bilateral. About $50 \%$ of PAAs are also associated with abdominal aortic aneurysm. Most are of atherosclerotic origin, but they can be mycotic or integrate into Marfan syndrome or Behçet's disease [3] [5].

At least $40 \%$ of PAAs are symptomatic and discovered during complications: pain, nerve or venous compression, rupture, or during the onset of acute ischemia [4] [5]. Asymptomatic aneurysms with good distal flow should be electively repaired although there are no prospective studies to support an unqualified recommendation in this regard particularly for aneurysms measuring less than 2 $\mathrm{cm}$ in diameter.

There is a published consensus that small PAAs rarely become symptomatic and that elective surgery should only be considered for those who are at least 2.0 $\mathrm{cm}$ in diameter. The natural history of PAAs is not fully documented by prospective anatomical studies. Over a five-year follow-up, the risk of ischemic complications was $36 \%$ in non-operated patients. The average growth rate of PAAs less than $20 \mathrm{~mm}$ was $1.5 \mathrm{~mm}$ per year, $3 \mathrm{~mm}$ between 20 and $30 \mathrm{~mm}$, and 3.7 $\mathrm{mm}$ per year for aneurysms greater than $30 \mathrm{~mm}$. In patients whose aneurysm was asymptomatic, the presence in isolation or in combination of three factors: parietal thrombus, diameter greater than $20 \mathrm{~mm}$, poor distal bed, was predictive of the occurrence of a progressive complication or an amputation and this justi- 
fied preventive surgery in patients whose life expectancy was sufficient. Small aneurysms less than $20 \mathrm{~mm}$ associated with distal occlusive lesions and lesions of parietal thrombosis, were more often responsible for critical ischemia. The therapeutic indications, in a patient with a popliteal aneurysm, should be made taking into account several factors: knowledge of the natural history of popliteal aneurysms; the nature of the lesion defined by Doppler ultrasound and angiography; the asymptomatic or symptomatic nature of the popliteal aneurysm; the presence of clinical complications pain, nerve or nerve compression; the occurrence of acute ischemia [4].

The primary goal of surgical treatment for PAA is the prevention of thromboembolic events, which can be complicated by limb ischemia and tissue loss. The second objective is to avoid their increase in volume responsible for compressive phenomena or even exceptional rupture. The popliteal fossa is a site of permanent flexion-extension in working life. Most lesions of the popliteal artery are located near the joint space. The inferior anastomosis of the bypass grafts is therefore located below the line. It is therefore necessary to use a substitute which ultimately tolerates bending without making kinks. The vein is certainly the best, but it is unavailable in $10 \%$ to $30 \%$ of cases [6], especially if veins smaller than $4 \mathrm{~mm}$ are excluded, since this is the minimum size required for bypass, especially in aneurysmal pathology where that of the arteries is generally above average [6]. In the absence of venous material, the transposition of the superficial femoral artery, replaced by a prosthetic segment in polytetrafluoroethylene (PTFE) or in Dacron, have a lower permeability rate than venous bypass, especially in infra-popliteal locations [6] [7]. The diameter of the implanted prosthesis should be greater than $6 \mathrm{~mm}$. Surgical treatment of isolated PAAs may be exclusion or flattening associated with bypass surgery. The most common procedure is a saphenous vein exclusion bypass. We know that the simple exclusion exposes the risk of seeing the aneurysm still fed by its collaterals and growing in size. This equivalent of type II endoleak may be responsible for venous or neurological compression, or even rupture of the aneurysm that remained in place [7]. In our case, we had carried out a flattening of the aneurysm, arterial continuity was restored by the interposition of an ipsilateral reverse saphenous graft. The endovascular approach is a more recent alternative which consists in placing inside the aneurysm of a self-expanding covered endoprosthesis making it possible to exclude the aneurysm while ensuring the patency of the popliteal axis and the distal vasculature. The results published in the first series of selected cases show good patency rates with reduced operating time and hospitalization [2]. Several studies have correlated the postoperative prognosis, depending on the symptomatic or asymptomatic nature of the aneurysm, the overlying occlusive lesions and the quality of the distal arterial network. The rate of primary patency and limb salvage was significantly greater than $60 \%$ in asymptomatic patients. In symptomatic patients, the results were better in claudicant patients than in patients with acute thrombosis or critical ischemia [4]. 


\section{Conclusion}

Popliteal artery aneurysms are a rare condition, but the most common of arterial aneurysms of the lower extremities. They can be bilateral or associate with an abdominal aortic aneurysm. There are two clinical presentations. In asymptomatic forms, the risk of amputation is high when there is a parietal thrombus, isolated or associated, a diameter greater than $20 \mathrm{~mm}$ and a poor distal bed. Symptomatic forms are characterized by the presence of pain, nerve or venous compression and the occurrence of acute ischemia. The rate of complications and mortality is higher in symptomatic patients than in asymptomatic patients. Surgical treatment for isolated popliteal artery aneurysms may be artery exclusion or flattening associated with bypass surgery. In the absence of venous material, transposition of the superficial femoral artery, replaced by a prosthetic segment, is a reliable alternative. However, there is a more recent alternative to surgery, which is endovascular treatment with covered stent placement.

\section{Informed Consent}

The informed consent form has been submitted and explained to the patient. He accepted and signed the form.

\section{Conflicts of Interest}

The authors declare no conflicts of interest regarding the publication of this paper.

\section{References}

[1] Labrousse, F. (1812) Dissertation sur l'anévrisme de l'artère poplitée, suivie d'une observation propre à l'auteur. Thèse de médecine No. 37, Faculté de Médecine de Paris, 26 mars, Vibrac.

[2] Lecorps de Tessy, G.-P. (1827) De l'anévrisme spontanée de l'artèrepoplitée. Thèse de Médecine No. 192, Faculté de Médecine de Paris, 4 août.

[3] van Ouwenaller, F., Corpataux, J.-M., Deglise, S. and Marty, B. (2015) Expérience monocentrique sur 5 ans de la chirurgie ouverte et du traitement endovasculaire dans la prise en charge des anévrismes de l'artère poplitée. Mémoire de Maitrise en médecine No. 1842. Université de Lausane, Faculté de biologie et de médecine.

[4] Ficelle, J.-M. and Cormier, F. (2007) Indications thérapeutiques des anévrismes poplités. Clinique Bizet, 23, rue Bizet, 75116 Paris, France. Actualités et perfectionnement.

[5] Hirsch, A.T., Haskal, Z.J., Hertzer, N.R., Bakal, C.W., Creager, M.A., Halperin, J.L., Hiratzka, L.F., Murphy, W.R.C., Olin, J.W., Puschett, J.B., Rosenfield, K.A., Sacks, D., Stanley, J.C., Taylor Jr., L.M. and White, C.J., White, J. and White, R.A. (2006) ACC/AHA 2005 Practice Guidelines for the Management of Patients with Peripheral Artery Disease (Lower Extremity, Renal, Mesenteric, and Abdominal Aortic). Circulation, 113, e463-654. https://doi.org/10.1161/CIRCULATIONAHA.106.174526

[6] Puppinck, P., Chevalier, J., Ducasse, E. and Dasnoy, D. (2004) L'autotransplantation de l'artere femorale superficielle dans les lesions arterielles polplitees. Journal des 
Maladies Vasculaires (Paris), 29, 9-11.

https://doi.org/10.1016/S0398-0499(04)96706-6

[7] Lemonnier, T., Feugier, P., Ricco, J.-B., de Ravignan, D. and Chevalier, J.-M. (2009) Lyon et Poitiers, France. Traitement des anévrismes poplités par greffon artériel fémoral: évaluation à long terme. Annals of Vascular Surgery, 23, 755-757.

https://doi.org/10.1016/j.acvfr.2010.03.013 